\title{
GROWTH DYNAMICS OF GRASS-SHRUB COMMUNITIES DURING EARLY FORMATIVE PERIOD
}

\author{
HUANG, G. ${ }^{1,2^{*}}-$ ZHENG, M. X. ${ }^{1 *}$ \\ ${ }^{1}$ Department of Civil Architecture College, East China Jiaotong University \\ Nanchang, China \\ ${ }^{2}$ Department of Civil and Architecture Engineering, Huanggang Normal University \\ Huanggang, China \\ ${ }^{*}$ Corresponding authors \\ e-mail: huanggang0317@163.com; zhengmingxin0317@yeah.net; phone:+86-134-0990-2162 \\ (Received $19^{\text {th }}$ Oct 2020; accepted $8^{\text {th }}$ Feb 2021)
}

\begin{abstract}
The formation of stable grass-shrub communities is the goal of highway slope ecological protection. However, the growth dynamics of grass-shrub communities during the early formative period is poorly explored, leading to a lack of available guiding. In this study, we carried out an ecological slope protection model of grass and shrubs, the following species were selected: Cynodon dactylon and Magnolia multiflora. We examined the dynamics of plant coverage (PD), plant density (PD), and plant height (PH) of the two plants affected by topographic factors (slope gradient and slope aspect) and seed schemes (grassshrub ratio and seed density). Moreover, we attempted to optimize the four influencing factors according to various $\mathrm{PC}, \mathrm{PD}$, and $\mathrm{PH}$. The results indicated that the PD of grass-shrub experimental group was significantly better than that of pure-grass and pure-shrub experimental groups during the early formative period. Significant spatial variation of PD was also found during the first two months. The peak PD for $45^{\circ}$ is 1.26-1.46 times higher than that for the other two slope gradients, $\mathrm{PD}$ of $C$. dactylon differed significantly with grass-shrub ratio $(\mathrm{P}<0.05)$. The $\mathrm{PH}$ of $C$. dactylon and $M$. multiflora was significantly affected by the slope aspect. In addition, the optimum conditions for the formulation of grass-shrub communities are as follows: slope gradient of $30^{\circ}-45^{\circ}$, slope aspect of south-facing, seed density of $20 \mathrm{~g} \cdot \mathrm{m}^{-2}$, grass-shrub ratio of $1: 9$.
\end{abstract}

Keywords: slope, ecological protection, grass-shrub vegetation, topographic factor, seed schemes, plant height

\section{Introduction}

With the rapid development of China's economic construction, a large number of mountains have been excavated in road construction projects (Cao et al., 2009). The original natural ecosystem has been seriously damaged, forming several exposed slopes (Cohen-Fernández and Naeth, 2013; Shao et al., 2014). When there is no vegetation cover and other engineering measures on the highway slope, ecological imbalance and geological disasters will occur frequently. To prevent the collapse, debris flow, soil erosion, and other geological disasters caused by the degradation of the ecological environment, it is necessary to restore and reconstruct the ecosystem under the guidance of human beings (Fan et al., 2013). In recent years, with raising awareness of environmental protection, ecological restoration with vegetation has been increasingly emphasized by some people (Yang et al., 2016). More recently, grass-shrub seed technology is gradually the hot spot of ecological protection for highway slope (Wang, 2014).

Several researchers have reported on research of grass and shrub growth in grass-shrub community formation (Chen et al., 2019). Many meaningful and interpretable growth 
parameters are often used to evaluate grass and shrub growth, such as plant coverage (PC), plant density (PD), and plant height (PH) (Allen, 1998; Gadi et al., 2019). Increasing PC can significantly control soil erosion (Fu et al., 2012). PC indicates the interception area of radial energy, which controls the evapotranspiration induced suction by leaves (Leung et al., 2015). Evapotranspiration induced suction governs the shallow stability of the vegetated slope ( $\mathrm{Liu}$ et al., 2018; Ni et al., 2018). The PD determines competition intensity to change in community formation ( $\mathrm{Li}$ et al., 2020). PH of grass and shrubs affects the biomass of vegetation, which affects the process of ecological restoration (Lei et al., 2016; Zhao et al., 2020). PH is presumed to be a constant growth factor in previous studies (Zhu and Zhang, 2015; Gadi et al., 2018). There are growth dynamics during grass-shrub community formation, and monitoring and assessing the status during vegetation restoration is essential when evaluating the restoration success for highway slope (Hobbs and Harris, 2001).

The growth dynamics of grass-shrub community formation are influenced by topographic factors and seed schemes. Researchers have reported that the growth of grass and shrub was affected by the slope gradient and slope aspect (Fang et al., 2018). Research revealed that the shrub had both positive and negative effects on the growth parameters of grass (Cavieres and Badano, 2009). Early survival of grass-shrub seeds was influenced due to competition between grass and shrubs (Manzaneda et al., 2005). The competition of seed density and grass-shrub ratio influences the PH (Olsen et al., 2006). The different grass-shrub ratio affected the number and diversity index of grass-shrub communities (Song, 2015). The spatial patterns of individuals were related to the PH of grass and shrubs (Zhao, 2020). Grass and shrubs have different survival rates at different grass-shrub ratios and seed density (Schob et al., 2013). Topographic factors (slope gradient and slope aspect) and seed schemes (grass-shrub ratio and seed density) are often accelerated or inhibited the formation of grass-shrub communities. Therefore, it is important to know how the four influencing factors affect grass-shrub community formation, because it will determine the successful use of grass-shrub communities in restoration projects. However, the current main research is about topographical factors affecting soil microbiological indicators (Teixeira et al., 2019) and radial growth of vegetation (Kim et al., 2017), and seed scheme focusing on the yield of agricultural crops (Freudenreich and Mußhoff, 2018). Little systematic attention has been paid to the effect of topographic factors and seed schemes on the dynamics of PC, PD, and PH.

In this paper, we carried out an ecological slope protection model of selected grass and shrubs, namely Cynodon dactylon and Magnolia multiflora. The objectives of the experimental study are the followings: (1) exploring the dynamics of PC, PD, and PH affected by two topographic factors (slope gradient and slope aspect) and two seed schemes (grass-shrub ratio and seed density); (2) optimizing the formulation of topographic factors and seed schemes for grass-shrub community formation or highway slope ecological restoration.

\section{Materials and methods}

\section{Materials}

The experiment was carried out at Hubei University of Technology, Wuhan, China. In this test model, 48 cement prefabricated plates $\left(1.5 \times 0.5 \times 0.05 \mathrm{~m}^{3}\right)$ and $0.5 \mathrm{~m}^{3}$ red brick were used to make the slope models. We designed four slopes $\left(15^{\circ}, 30^{\circ}, 45^{\circ}\right.$, and $\left.60^{\circ}\right)$ according to the slopes of the most practical engineering. Two slope aspects (north-facing and south-facing) 
were arranged (Fig. 1a). The model of each slope gradient contains 12 experimental groups, of which three slope gradients $\left(15^{\circ}, 30^{\circ}\right.$, and $\left.60^{\circ}\right)$ are 6 experimental groups in the two slope aspects, and the $45^{\circ}$ slope is north-facing $(\mathrm{N})$ of 12 experimental groups. The area of each experimental group was $1.5 \times 0.5 \mathrm{~m}^{2}$. The total thickness is $150 \mathrm{~mm}$, which can be divided into three layers: the bottom layer is the prefabricated plate with a thickness of $50 \mathrm{~mm}$; the middle layer is the soil layer with a thickness of $90 \mathrm{~mm}$; the topmost layer is the soil overburden layer with a thickness of $10 \mathrm{~mm}$. After investigation of plenty of engineering slopes, the grass was chosen $(C$. dactylon), and the shrub was chosen ( $M$. multiflora). The vitality of these two plants is particularly strong, suitable for slope restoration. The soil used for the tests was excavated at a depth of $10 \mathrm{~cm} \sim 30 \mathrm{~cm}$ below the surface, from the bank of the Xunsi River in Wuhan city, and the soil area was $40 \mathrm{~m}^{2}$. To provide initial soil fertility, the same fertilizer was added to all experimental groups.

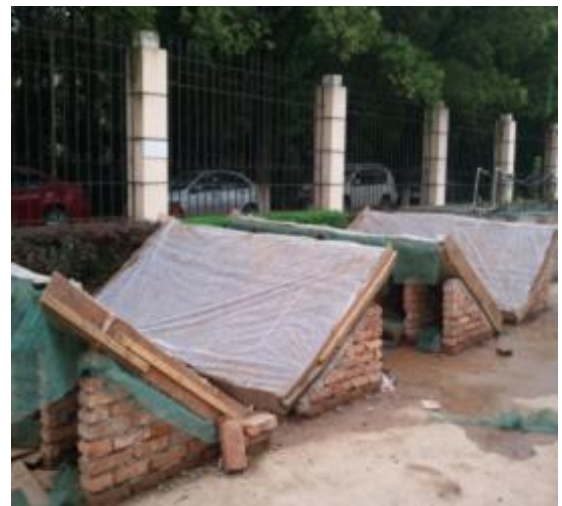

(a)

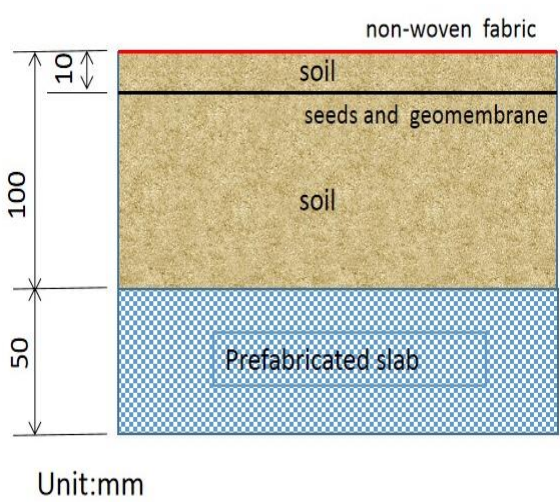

(b)

Figure 1. (a) Experimental group, (b) Profile of experimental group

\section{Full-factorial experiments}

In this test, the ecological slope protection model was carried out under outdoor conditions. A full-factorial experiment method was adopted to explore the optimal ratio of the four components evaluated in this study using four test levels (Table 1). These fullfactorial experiments produced forty-eight different mix compositions. The test design is shown in Table 2.

Table 1. Factors and level values

\begin{tabular}{c|c|c|c|c}
\hline \multirow{2}{*}{ Test level } & \multicolumn{4}{|c}{ Factors } \\
\cline { 2 - 5 } & Slope gradient $\left(^{\mathbf{}}\right)$ & Slope aspect & seed density $\left(\mathbf{g} \cdot \mathbf{m}^{-\mathbf{2}}\right)$ & grass-shrub ratio \\
\hline 1 & 15 & $\mathrm{~N}$ & 15 & $1: 0$ \\
2 & 30 & $\mathrm{~S}$ & 20 & $1: 3$ \\
3 & 45 & - & 25 & $1: 9$ \\
4 & 60 & - & - & $0: 1$ \\
\hline
\end{tabular}

The soil needed to go through three procedures (dried, crushed, and screened for $10 \mathrm{~mm}$ ) before it was placed on the prefabricated plates. The soil thickness was identical for each experimental group. Plant seed was first weighed and soaked in distilled water for $12 \mathrm{~h}$, then evenly sowed on the soil. Finally, $10 \mathrm{~mm}$ thick soil and a layer of non-woven fabric covered the vegetation seeds. The profile of the experimental group is shown in Fig. 1 b. 
Table 2. Testing program for the experimental group

\begin{tabular}{c|c|c|c|c|c|c|c|c|c}
\hline Mix & $\begin{array}{c}\text { Slope } \\
\text { gradient } \\
(\mathbf{(})\end{array}$ & $\begin{array}{c}\text { Slope } \\
\text { aspect }\end{array}$ & $\begin{array}{c}\text { Seed } \\
\mathbf{d e n s i t y} \\
\left(\mathbf{g} \cdot \mathbf{m}^{-2} \mathbf{)}\right.\end{array}$ & $\begin{array}{c}\text { Grass- } \\
\text { shrub } \\
\text { ratio }\end{array}$ & Mix & $\begin{array}{c}\text { Slope } \\
\text { gradient } \\
(\mathbf{(})\end{array}$ & $\begin{array}{c}\text { Slope } \\
\text { aspect }\end{array}$ & $\begin{array}{c}\text { Seed } \\
\mathbf{d e n s i t y} \\
\left(\mathbf{g} \cdot \mathbf{m}^{-2} \mathbf{)}\right.\end{array}$ & $\begin{array}{c}\text { Grass- } \\
\text { shrub ratio }\end{array}$ \\
\hline $1 \#$ & 15 & $\mathrm{~S}$ & 15 & $1: 0$ & $25 \#$ & 45 & $\mathrm{~N}$ & 15 & $1: 0$ \\
$2 \#$ & 15 & $\mathrm{~S}$ & 15 & $1: 3$ & $26 \#$ & 45 & $\mathrm{~N}$ & 15 & $1: 3$ \\
$3 \#$ & 15 & $\mathrm{~S}$ & 15 & $1: 9$ & $27 \#$ & 45 & $\mathrm{~N}$ & 15 & $1: 9$ \\
$4 \#$ & 15 & $\mathrm{~S}$ & 15 & $0: 1$ & $28 \#$ & 45 & $\mathrm{~N}$ & 15 & $0: 1$ \\
$5 \#$ & 15 & $\mathrm{~S}$ & 20 & $1: 0$ & $29 \#$ & 45 & $\mathrm{~N}$ & 20 & $1: 0$ \\
$6 \#$ & 15 & $\mathrm{~S}$ & 20 & $1: 3$ & $30 \#$ & 45 & $\mathrm{~N}$ & 20 & $1: 3$ \\
$7 \#$ & 15 & $\mathrm{~N}$ & 20 & $1: 9$ & $31 \#$ & 45 & $\mathrm{~N}$ & 20 & $1: 9$ \\
$8 \#$ & 15 & $\mathrm{~N}$ & 20 & $0: 1$ & $32 \#$ & 45 & $\mathrm{~N}$ & 20 & $0: 1$ \\
$9 \#$ & 15 & $\mathrm{~N}$ & 25 & $1: 0$ & $33 \#$ & 45 & $\mathrm{~N}$ & 25 & $1: 0$ \\
$10 \#$ & 15 & $\mathrm{~N}$ & 25 & $1: 3$ & $34 \#$ & 45 & $\mathrm{~N}$ & 25 & $1: 3$ \\
$11 \#$ & 15 & $\mathrm{~N}$ & 25 & $1: 9$ & $35 \#$ & 45 & $\mathrm{~N}$ & 25 & $1: 9$ \\
$12 \#$ & 15 & $\mathrm{~N}$ & 25 & $0: 1$ & $36 \#$ & 45 & $\mathrm{~N}$ & 25 & $0: 1$ \\
$13 \#$ & 30 & $\mathrm{~S}$ & 15 & $1: 0$ & $37 \#$ & 60 & $\mathrm{~S}$ & 15 & $1: 0$ \\
$14 \#$ & 30 & $\mathrm{~S}$ & 15 & $1: 3$ & $38 \#$ & 60 & $\mathrm{~S}$ & 15 & $1: 3$ \\
$15 \#$ & 30 & $\mathrm{~S}$ & 15 & $1: 9$ & $39 \#$ & 60 & $\mathrm{~S}$ & 15 & $1: 9$ \\
$16 \#$ & 30 & $\mathrm{~S}$ & 15 & $0: 1$ & $40 \#$ & 60 & $\mathrm{~S}$ & 15 & $0: 1$ \\
$17 \#$ & 30 & $\mathrm{~S}$ & 20 & $1: 0$ & $41 \#$ & 60 & $\mathrm{~S}$ & 20 & $1: 0$ \\
$18 \#$ & 30 & $\mathrm{~S}$ & 20 & $1: 3$ & $42 \#$ & 60 & $\mathrm{~S}$ & 20 & $1: 3$ \\
$19 \#$ & 30 & $\mathrm{~N}$ & 20 & $1: 9$ & $43 \#$ & 60 & $\mathrm{~N}$ & 20 & $1: 9$ \\
$20 \#$ & 30 & $\mathrm{~N}$ & 20 & $0: 1$ & $44 \#$ & 60 & $\mathrm{~N}$ & 20 & $0: 1$ \\
$21 \#$ & 30 & $\mathrm{~N}$ & 25 & $1: 0$ & $45 \#$ & 60 & $\mathrm{~N}$ & 25 & $1: 0$ \\
$22 \#$ & 30 & $\mathrm{~N}$ & 25 & $1: 3$ & $46 \#$ & 60 & $\mathrm{~N}$ & 25 & $1: 3$ \\
$23 \#$ & 30 & $\mathrm{~N}$ & 25 & $1: 9$ & $47 \#$ & 60 & $\mathrm{~N}$ & 25 & $1: 9$ \\
$24 \#$ & 30 & $\mathrm{~N}$ & 25 & $0: 1$ & $48 \#$ & 60 & $\mathrm{~N}$ & 25 & $0: 1$ \\
\hline & & & & & & & & &
\end{tabular}

\section{Experiment monitoring design}

The purpose of the test monitoring program was to quantify the dynamics of PC, PD, and PH. The monitoring period of the test was 32 months, from May 2013 to December 2015. Depending on the climate monitoring during the experiment, monthly rainfalls are shown in Fig. 2. In three years, the precipitation from January to May and August to December was less than $100 \mathrm{~mm}$, in the dry period. The rainfall in June and July was more than $250 \mathrm{~mm}$, which was a wet period.

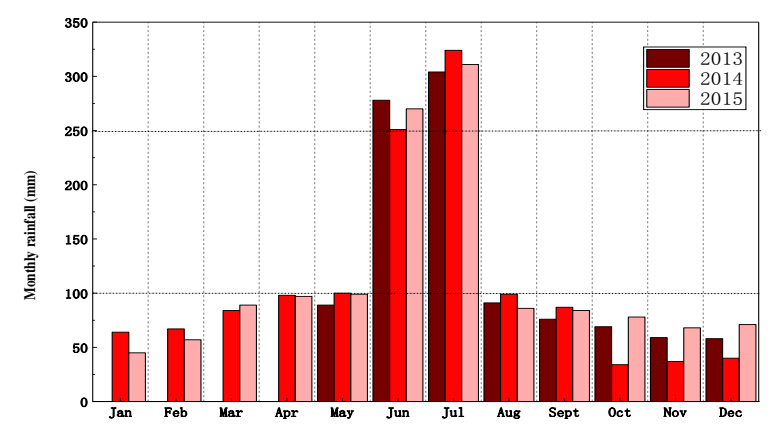

Figure 2. Monthly rainfall

The method of measuring the PC was to take photos of the test block with a SLR camera. To quantitatively analyze the spatial dynamics of PC, the green color was re- 
colored into black and the rest of the colors were re-colored into white using the software IPP 6.0 (Yang et al., 2019), as shown in Fig. 3. The PC in this study is the total PC generated by the grass and shrub canopy (the sheltered area of shrub to grass is not calculated repeatedly). The calculated black area by the software was the projected area of vegetation, which was used to calculate PC according to the formula:

$$
\mathrm{C}=\frac{\sum_{i=1}^{n} A_{i}}{A_{S}}
$$

where, $C$ denotes the area $\mathrm{PC}, A_{s}$ denotes the total area, $A_{i}$ denotes the projected area of a vegetation.
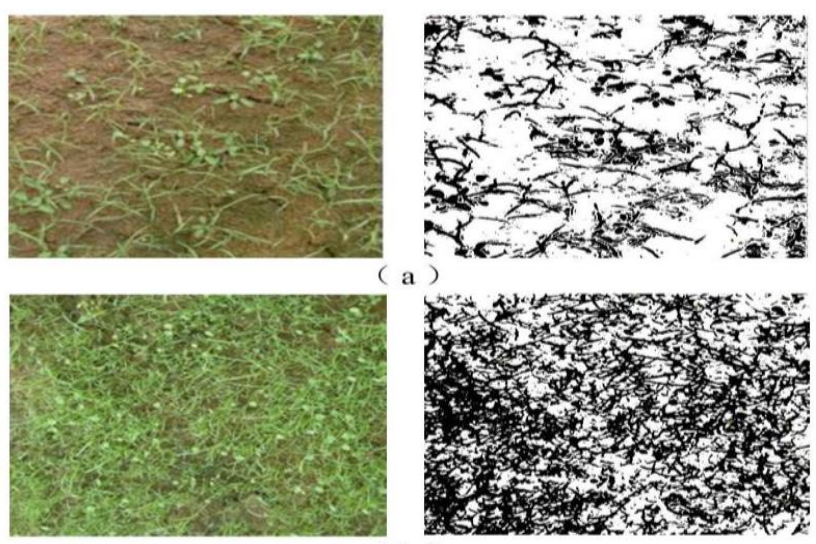

(b )

Figure 3. Vegetation and their projected areas (test 2\#). (a) Growth status in May30, 2013, (b) Growth status in June 30, 2013

The method of obtaining PD was to measure the number of grass and shrubs in the range of $1 \mathrm{dm}^{2}$. PH of grass and shrubs needed to be measured with a tape. PC and PH were measured every three days for the first 20 days, every seven days for 20 days to three months, and every month after three months. PC and PH are the average of three measurements in each time monitoring.

\section{Data analysis}

Differences in PC, PD, and PH were determined using ANOVA with LSD test. Paired t-tests were used to test differences in PC, PD, and PH for December 2015 between the two topographic factors and two seed schemes. All statistical tests were performed using IBM SPSS statistics 23.

\section{Results and Discussion}

\section{Dynamics of vegetation cover during the monitoring period}

Fig. 4a- $f$ shows the dynamics of vegetation cover in different stages. In May, the surface area covered by vegetation of the entire experimental group was relatively low (Fig. 4a). In June, the cover of $C$. dactylon increased rapidly, but the surface area was observed to be relatively low in pure-shrub experimental group (Fig. $4 b$ ). Grass-shrub experimental groups withered at a few locations, and $C$. dactylon withered more seriously than $M$. multiflora 
during July. Furthermore, we observed traces of rain erosion and exposure of the geonet in pure-shrub and pure-grass experimental groups. Unlike pure-shrub or pure-grass experimental groups, we noted relatively high resistance to erosion in grass-shrub experimental groups during heavy rain. This is probably because a combination of $C$. dactylon and M. multiflora. $C$. dactylon can slow runoff erosion. The stems and leaves of $M$. multiflora can play the role of rainfall interception and gravitational potential energy. In August, we observed the regrowth of $C$. dactylon. Changes in grass-shrub vegetation cover were relatively small from September to October. In addition, we observed that the cover area was relatively high in grass-shrub and experimental groups. This may be attributed to the relatively high water retention in grass-shrub experimental group during the monitoring period. The surface area of grass-shrub cover can avoid direct exposure to sunlight. The drought resistance of grass-shrub experimental group is stronger than that of the pure-shrub experimental group. The variation in grass-shrub experimental group cover was less during August and December, indicating that the grass-shrub communities tend to be stable. However, we observed wilting of $C$. dactylon from November to December (see Fig. $4 c-d$ ).

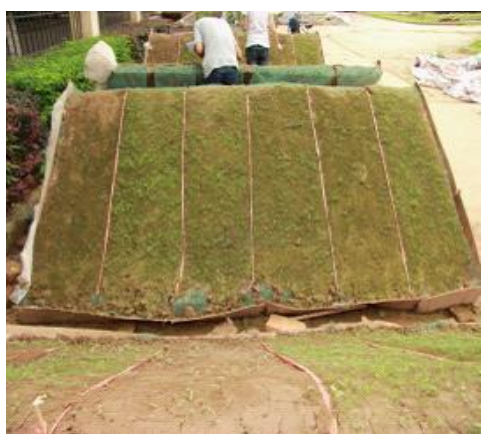

(a)

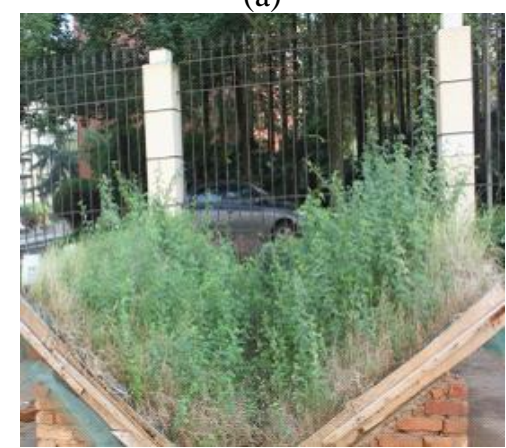

(c)

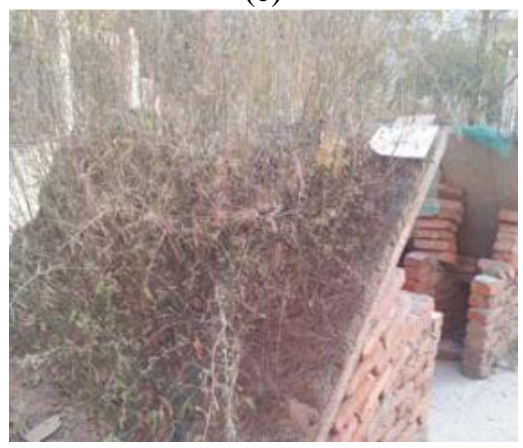

(e)

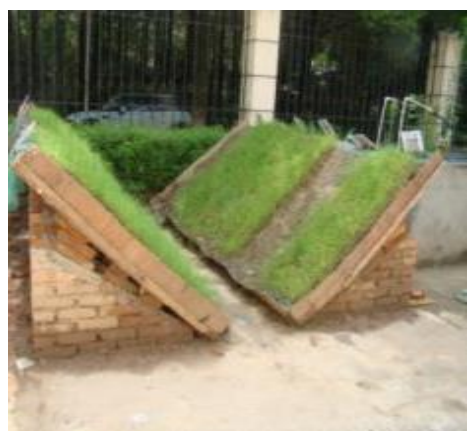

(b)

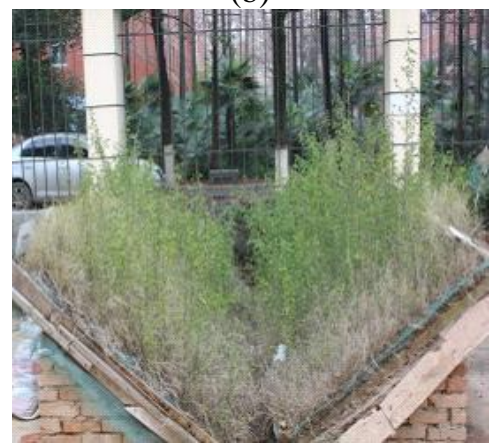

(d)

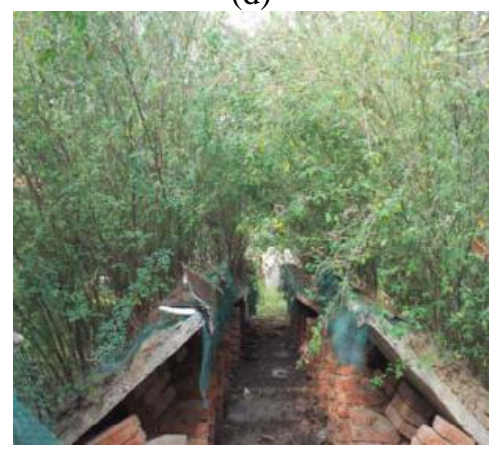

(f)

Figure 4. Changes in vegetation cover at different times (a) May 30, 2013, (b) June 30, 2013, (c) October 30, 2013, (d) November 30, 2013, (e) December 30, 2014, (f) November 30, 2015 
From March to May 2014, most of the withered $C$. dactylon regrow, and a certain number of C. dactylon sprouted. From November 2014 to January 2015, C. dactylon and M. multiflora withered, resulting in reduced stem and leaves (see Fig. 4e). This may be due to the lack of rainfall in the two months of the year and insufficient soil moisture, which caused grass and shrub plants to wither. Most of the $C$. dactylon and M. multiflora began to resurrect in March 2015, and a few C. dactylon sprouted. In December 2015, a small amount of $C$. dactylon withered, but M. multiflora did not wither (see Fig. $4 f$ ).

\section{PC during the monitoring period}

$\mathrm{PC}$ is an important indicator to measure the condition of surface vegetation. Spatial and temporal variations of the PC are plotted in Fig. 5. From Fig. 5, we note that the PC curves exhibit two stages: (1) The rapid rise stage: in the first two months, the PC of all experimental groups increases to 48.28-100\% range. Rapid change of PC indicates that the germination and initial growth of vegetation are mainly concentrated in May and June 2013. (2) Small fluctuation stage: the PC curve changes with season. In winter (October to February of the next year), the PC decreased by less than $10 \%$, while in the winter of 2014 (October to February of the next year), the PC dropped by $15-20 \%$. This may be because the $C$. dactylon and $M$. multiflora partially wither in winter, especially when plenty of leaves of M. multiflora fall, the PC reduces. The winter rainfall in 2014 was $30 \%$ less than that in previous years, which led to the withering of the two plantations to a certain extent and reduced the PC. In the spring and summer of 2014 and 2015 (March to August), the germination and new leaves of $C$. dactylon and $M$. multiflora increased the PC.

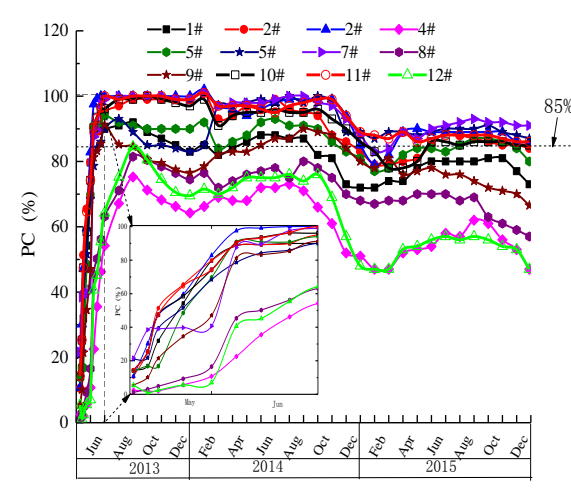

(a)

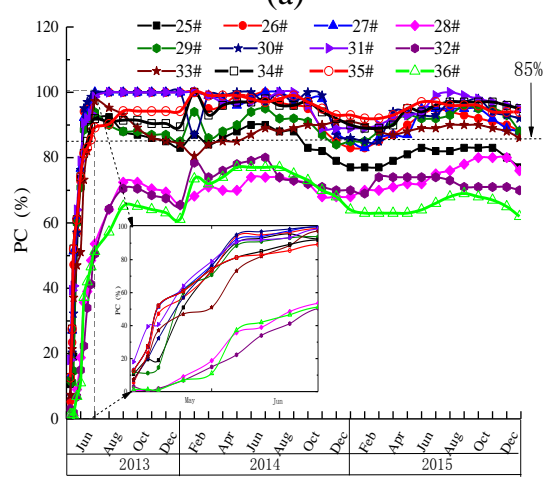

(c)

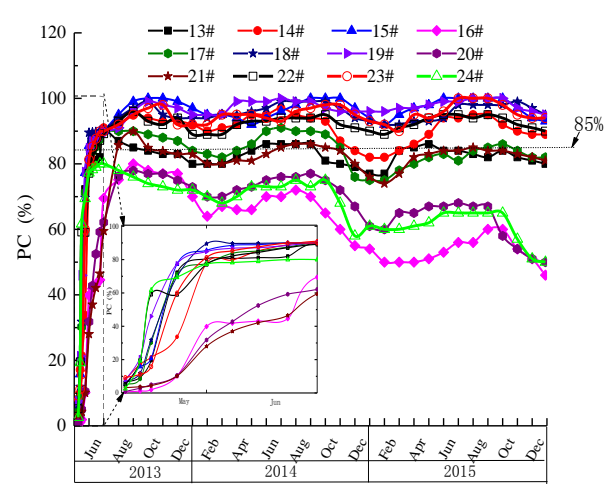

(b)

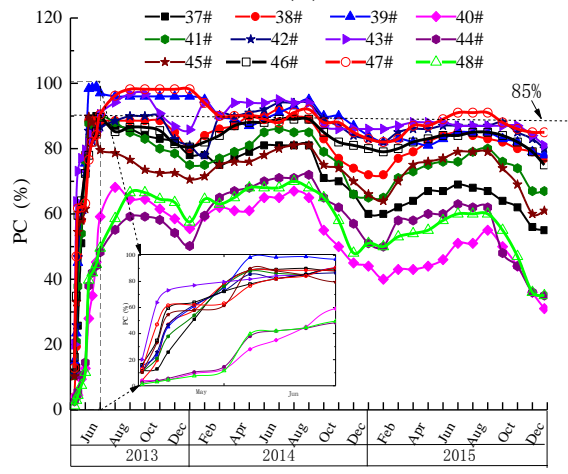

(d)

Figure 5. PC of experimental groups during the monitoring period (a) $15^{\circ}$, (b) $30^{\circ}$, (c) $45^{\circ}$, (d) $60^{\circ}$ 
As can be observed in Fig. 5, the PC of grass-shrub experimental group is greater than that of pure-grass and pure-shrub experimental group, the PC of pure-grass experimental group is higher than that of pure-shrub experimental group. In December 2015, the slope gradients with the highest average PC were $30^{\circ}(93.44 \%)$, followed by $45^{\circ}(90.46 \%), 15^{\circ}$ $(87.42 \%)$, and $60^{\circ}(78.41 \%)$ in grass-shrub experimental groups. According to the above analysis, the average PC first increases and then decreases with the increase of slope gradient. We use $85 \% \mathrm{PC}$ to indicate the turfgrass establishment of the vegetated communities (Vietor et al., 2010). From July 2013 to December 2014, all grass-shrub experimental groups and some pure-grass experimental groups reached turfgrass establishment. After December 2014, only the grass-shrub experimental group reached turfgrass establishment, the PC of all pure-shrub experimental group and pure-grass experimental groups ranged from $32.18 \%$ to $83.95 \%$, which has not reached the turfgrass establishment. Thus, we can conclude that the proper grass-shrub combination and proper slope gradient $\left(30-45^{\circ}\right)$ are beneficial to increase PC.

Next ANOVA method was applied to analyze differences in PC, PC differed insignificantly with slope gradient $(\mathrm{P}=0.233)$, slope aspect $(\mathrm{P}=0.09)$, and seed density $(\mathrm{P}=0.203)$. $\mathrm{PC}$ differed significantly with grass-shrub ratio $(\mathrm{P}<0.05)$.

\section{Dynamics of PD affected by topographic factors (slope gradient and slope aspect)}

7\#, 19\#, 31\#, and 43\#experimental groups were selected (1:9 of grass-shrub ratio, $\mathrm{N}$ of slope aspect, and $20 \mathrm{~g} \cdot \mathrm{m}^{-2}$ of seed density) to study the dynamics of PD affected by slope gradient. The curves of PD in experimental groups under different slope gradients are plotted in Fig. 6. It can be observed from Fig. 6 that the germination rate of $M$. multiflora is faster than that of $C$. dactylon. The PD curves of the two plants reach the maximum in one month and then generally decrease slowly.

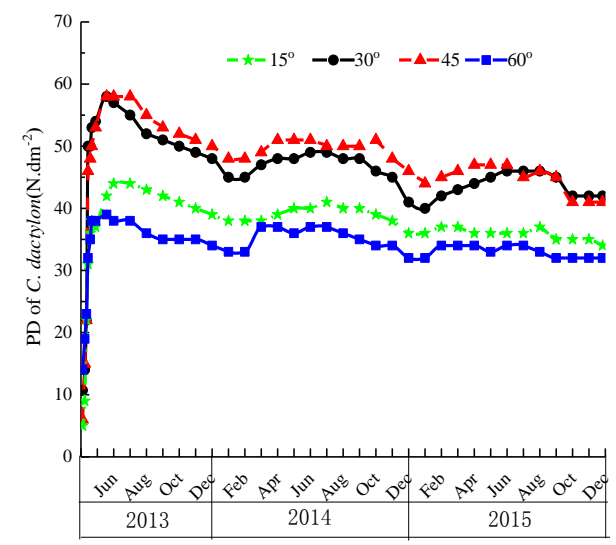

(a)

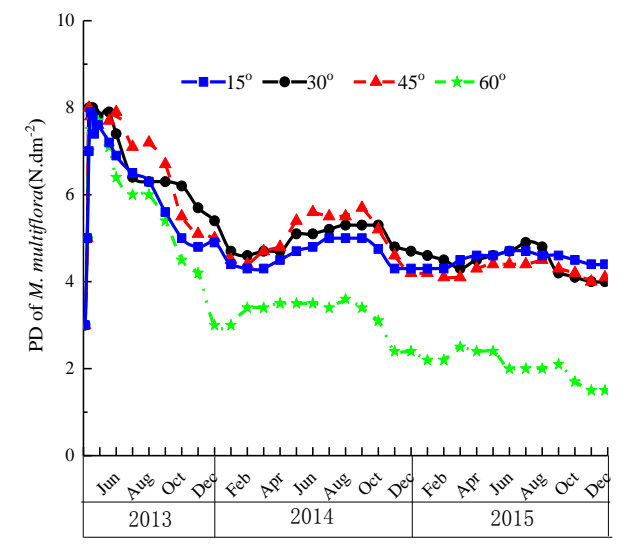

(b)

Figure 6. Change of $P D$ in experimental groups under different slope gradients (a) C. dactylon, (b) M. multiflora

As can be seen from Fig. $6 a$, the PD of $C$. dactylon decreased in winter (from November to February) and increased in spring (from April to July), but the variation of PD is only within $15 \%$. We note that the PD of $C$. dactylon first increases and then decreases with the increase of the slope gradient, and the slope gradient of $C$. dactylon highest PD was $45^{\circ}$. Furthermore, The PD of $45^{\circ}\left(57 \mathrm{~N} \cdot \mathrm{dm}^{-2}\right)$ is 1.46 and 1.26 times 
higher than that of $60^{\circ}\left(39 \mathrm{~N} \cdot \mathrm{dm}^{-2}\right)$ and $15^{\circ}\left(45 \mathrm{~N} \cdot \mathrm{dm}^{-2}\right)$ on June 30, 2013. This phenomenon is mainly due to increased sunlight. At medium and low slope gradients, the energy exposed to sunlight increases with the increasing of the slope gradient. When the slope gradient is greater than $45^{\circ}$, the germination and growth are hindered by insufficient water retention on the slope, thereby leading to reduced PD.

From Fig. 6b, the average PD of M. multiflora fell from 7.9 to 4.5 from August to December 2013. The low early survival rate of $M$. multiflora is mainly due to the dry period from August to December and the lack of water for the survival of $M$. multiflora. A small number of re-germinated $M$. multiflora appeared in the spring of 2014, a few M. multiflora died in the winter of 2014, the PD of M. multiflora became stable after 2015. The PD of the $60^{\circ}$ slope is significantly lower than that of the other three slopes, indicating that the high slope is not conducive to the growth of $M$. multiflora. There were insignificant differences in $\mathrm{PD}$ of $C$. dactylon $(\mathrm{P}=0.06)$ and $M$. multiflora at different slope gradients $(\mathrm{P}=0.12)$.

Next, to explore PD variation affected by the two slope aspects, we considered the $18 \#$ and 30\# experimental groups (1:9 of grass-shrub ratio, $30^{\circ}$ and $45^{\circ}$ of slope gradient, and $20 \mathrm{~g} \cdot \mathrm{m}^{-2}$ of seed density). As can be seen from Fig. 7a, the PD of C. dactylon with 18\# $(\mathrm{S})$ is greater than that with $18 \#(\mathrm{~N})$, and the difference between the two experimental groups increases with time. There are significant differences in PD of $C$. dactylon at different slope aspects $(P<0.05)$. From Fig. $7 b$, the slope aspect has little effect on the PD of M. multiflora.

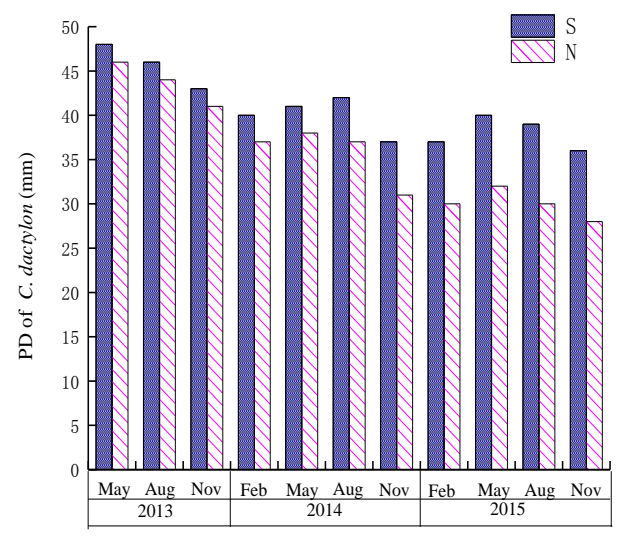

(a)

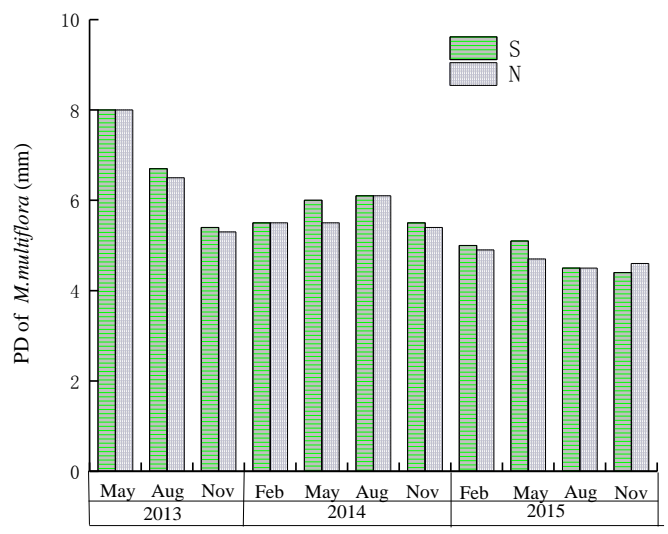

(b)

Figure 7. Variation of PD affected by two slope aspects (a) C. dactylon, (b) M. multiflora

\section{PD affected by seed schemes (seed density and grass-shrub ratio)}

Fig. 8 depicts the histogram of PD for the $45^{\circ}$ experimental slopes (25\#-36\#) in December 2015. We observed from Fig. $8 a$ that PD of $C$. dactylon is observed to rise with increasing seed density. Seed density for the highest average PD of $C$. dactylon is $25 \mathrm{~g} \cdot \mathrm{m}^{-2}\left(41.67 \mathrm{~N} \cdot \mathrm{dm}^{-2}\right)$, which is 1.59 and 1.09 times higher than that of $15 \mathrm{~g} \cdot \mathrm{m}^{-2}(26.17$ $\left.\mathrm{N} \cdot \mathrm{dm}^{-2}\right)$ and $20 \mathrm{~g} \cdot \mathrm{m}^{-2}\left(38.07 \mathrm{~N} \cdot \mathrm{dm}^{-2}\right)$. From Fig. 8, comparing the PD of C. dactylon and M. multiflora with $25 \mathrm{~g} \cdot \mathrm{m}^{-2}$ and $20 \mathrm{~g} \cdot \mathrm{m}^{-2}$, we note that the difference in average PD is very small. This result suggests that $25 \mathrm{~g} \cdot \mathrm{m}^{-2}$ cannot bring more $C$. dactylon PD. Thus, we can conclude that from an economic point of view, $20 \mathrm{~g} \cdot \mathrm{m}^{-2}$ is the best choice for the PD of C. dactylon. 


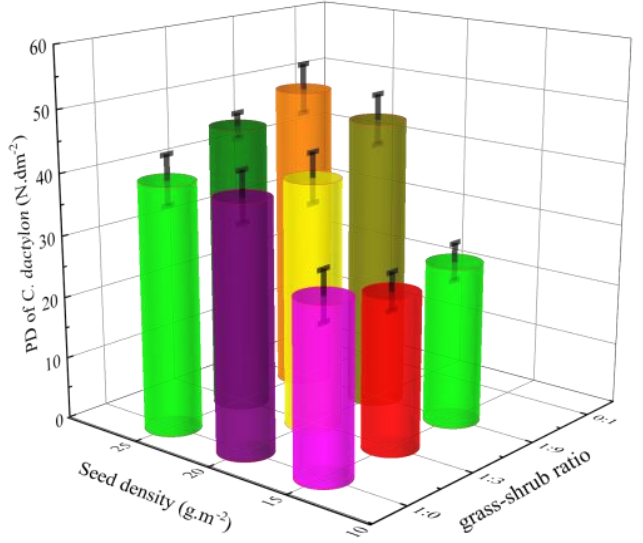

(a)

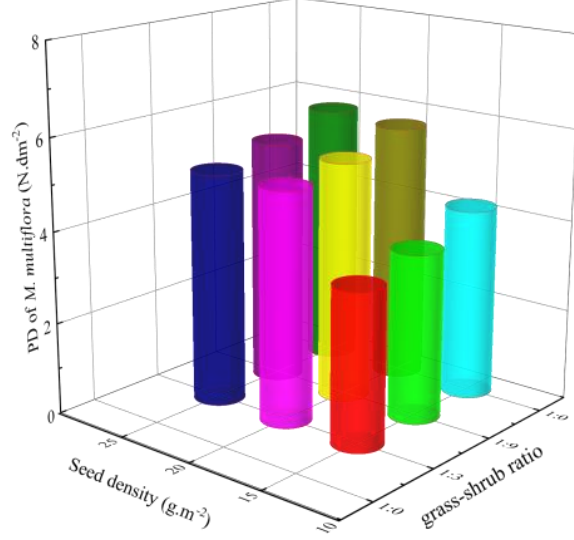

(b)

Figure 8. Variation of average PD affected by different seed density and grass-shrub ratio (a)

C. dactylon (b) M. multiflora

Meanwhile, PD of $C$. dactylon does not decrease significantly with the increasing of grass-shrub ratio, PD of $M$. multiflora increases with the increase of grass-shrub ratio. It can infer that more shrub seeds account for more total PD. PD differed significantly with grass-shrub ratio $(\mathrm{P}<0.05)$.

\section{Dynamics of PH affected by topographic factors (slope gradient and slope aspect)}

We plot the PH curves of $C$. dactylon and M. multiflora obtained from 7\#, 19\#, 31\#, and 43\# experimental groups (, 1 : , and $20 \mathrm{~g} \cdot \mathrm{m}^{-2}$ ) in Fig. 9. From Fig. 9, C. dactylon grew faster before mid-May 2013, and the correlation between PH and time is linear. We found that $\mathrm{PH}$ of $C$. dactylon is relatively slow during mid-May and September 2013, which is only about $20 \mathrm{~mm}$ in three months. This result indicates that $C$. dactylon has stopped growing, which is consistent with the growth mechanism. We note that the PH of $C$. dactylon were reduced in July 2013. This is probably because the heavy rainfall seriously affected the seedling stage of the $C$. dactylon. Notably, the decrease of PH can be observed from October 2013 to February 2014, from October 2014 to February 2015, and from October 2015 to December 2015. Consequently, we can conclude that heavy rainfall and low temperature and dry climate have a great impact on the vegetation growth.

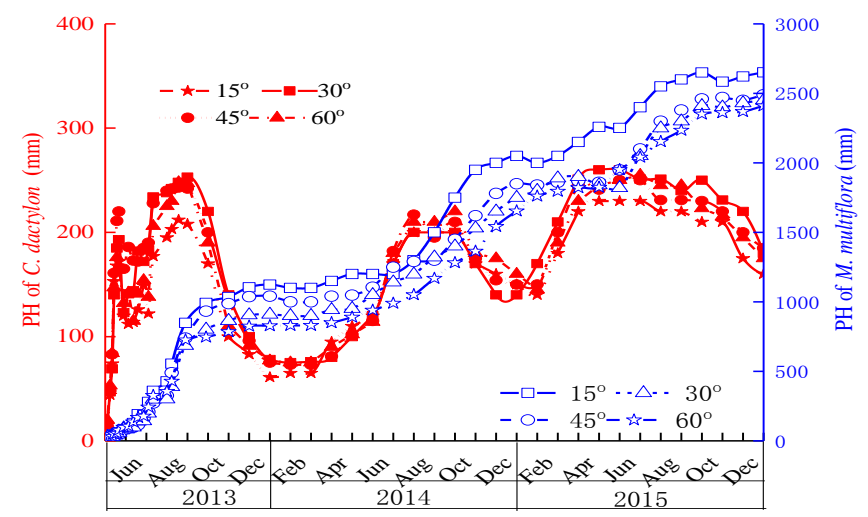

Figure 9. Variation of PH affected by different slope gradients 
From Fig. 9b, we observed that the PH curves of M. multiflora exhibit a four -stage nonlinear relationship: (a) the first stage is before July 2013, M. multiflora grows rather slowly, with a total growth of $580 \mathrm{~mm}$. (b) The second stage is from August to September 2013 M. multiflora growing faster. Four experimental groups have grown $540 \mathrm{~mm}$ every month. (c) From October 2013 to February 2014 is the third stage, when M. multiflora growth slows down. $M$. multiflora grows $100 \mathrm{~mm}$ in five months. (d) The fourth stage is after May 2014, M. multiflora grows faster, but the growth rate is lower than that in the second stage and slows down in winter. This result indicates that the fastest growing time of $M$. multiflora is from the fifth month to the next spring/summer. In addition, the slope gradient with the highest average $\mathrm{PH}$ of $M$. multiflora is $15^{\circ}(1064 \mathrm{~mm})$ during September and December 2013, which is 1.06, 1.22, and 1.34 times higher than that $30^{\circ}$ $(1000 \mathrm{~mm}), 45^{\circ}(869 \mathrm{~mm})$ and $60^{\circ}(796 \mathrm{~mm})$. PH of C. dactylon and M. multiflora differed insignificantly with the slope gradient $(\mathrm{P}>0.05)$.

Next, to analyze the variation of PH affected by the two slope aspects, we considered the 18\# and 30\# experimental groups (1:9 of grass-shrub ratio, $30^{\circ}$ and $45^{\circ}$ of slope gradient and $20 \mathrm{~g} \mathrm{~m}^{-2}$ of seed density). From Fig. 10, we note that the slope aspect affects the $\mathrm{PH}$ of plants, and the difference of $\mathrm{PH}$ between the north-facing and south-facing increases with time. In December 2015, the $\mathrm{PH}$ of $C$. dactylon were $151 \mathrm{~mm}$ (south-facing), which is 1.13 times higher than that of $107 \mathrm{~mm}$ (north-facing). The $\mathrm{PH}$ (south-facing) of $M$. multiflora is 1.25 times higher than that (north-facing). The PH of $C$. dactylon and $M$. multiflora differed significantly with the slope aspect $(P<0.05)$, which can be attributed to the positive effects of the vailing winds from the southeast in summer (Zhou et al., 2016).
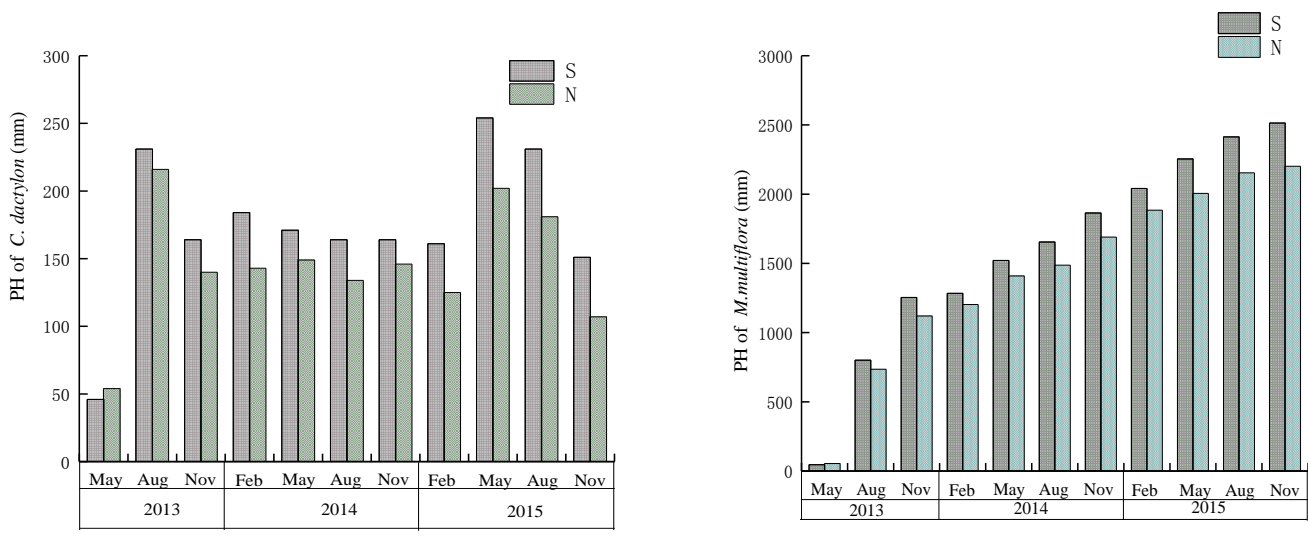

Figure 10. Variation of PH affected by two slope aspects

\section{Dynamics of PH affected by seed schemes (grass-shrub ratio and seed density)}

To understand the significance of the change in competition between grass and shrub, we considered four experimental groups (29\#, 30\#, 31\#, and 32\#) with the same factors $\left(45^{\circ}, \mathrm{N}, 20 \mathrm{~g} \cdot \mathrm{m}^{-2}\right)$. Dynamics of $\mathrm{PH}$ affected by the four grass-shrub ratios are plotted in Fig. 11. We found that the $\mathrm{pH}$ difference between $C$. dactylon and M. multiflora was very small in the four experimental groups before August 2013, but the difference between the $\mathrm{PH}$ of pure-grass experimental group and grass-shrub experimental group increased with time after September 2013. As the time and the grass-shrub ratio increase, the $\mathrm{pH}$ value of $M$. multiflora also increases. We observe that the PH of $C$. dactylon for 1:3 (1:9) was 
greater than $50 \mathrm{~mm}(60 \mathrm{~mm})$ of 1:0 in December 2015. The PH of M. multiflora for 0:1 is 1.10 times that for $0: 1$ and 1.35 times that for $0: 1$. Consequently, we can conclude that the higher grass-shrub ratio is beneficial to the growth of $C$. dactylon and M. multiflora. $\mathrm{PH}$ differed insignificantly with grass-shrub ratio $(\mathrm{P}>0.05)$.
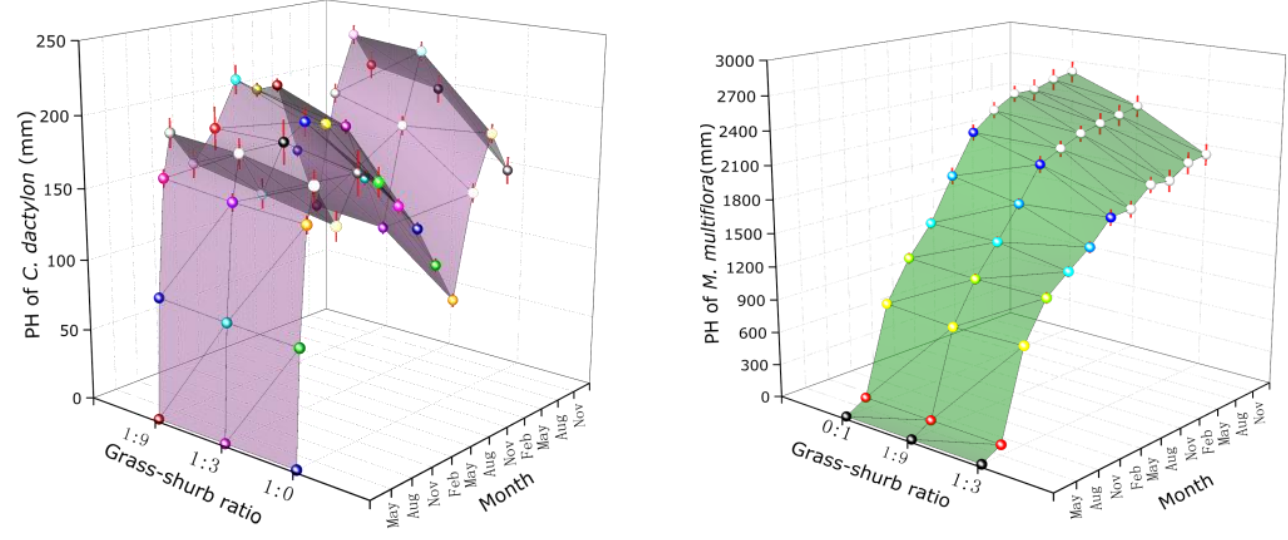

Figure 11. Dynamics of PH affected by different grass-shrub ratio

We plot the PH curves of $C$. dactylon and M. multiflora obtained from 27\#, 31\#, and 35\# experimental groups $\left(45^{\circ}, \mathrm{N}, 1: 9\right)$ in Fig. 12. From Fig. 12a, we observed that the relationship between $\mathrm{PH}$ of $C$. dactylon with seed density was not as obvious during the first two months. The $\mathrm{PH}$ difference of $C$. dactylon with different seed densities was not significant, and the $\mathrm{PH}$ difference of different seed densities of $M$. multiflora increased with time (see Fig. 12b). PH of M. multiflora decreased with the increasing of seed density. Seed density with the highest average growth height of $M$. multiflora is $20 \mathrm{~g} \cdot \mathrm{m}^{-2}$ $(2464 \mathrm{~mm})$, followed by $25 \mathrm{~g} \cdot \mathrm{m}^{-2}(2286 \mathrm{~mm})$ and $15 \mathrm{~g} \cdot \mathrm{m}^{-2}(1830 \mathrm{~mm})$ in December 2015 . The PH of M. multiflora to $20 \mathrm{~g} \cdot \mathrm{m}^{-2}$ is 1.07 times higher than that to $25 \mathrm{~g} \cdot \mathrm{m}^{-2}$. The results indicated that more than $20 \mathrm{~g} \cdot \mathrm{m}^{-2}$ of seed density had a negative effect on the $\mathrm{PH}$ of M. multiflora. Excessive seed leads to increased competition among vegetation. The nutrients and water obtained from the soil of vegetation may be reduced. Consequently, we can conclude that excessive seed density will have a negative impact on $\mathrm{PH}$. PH differed insignificantly with seed density $(\mathrm{P}>0.05)$.
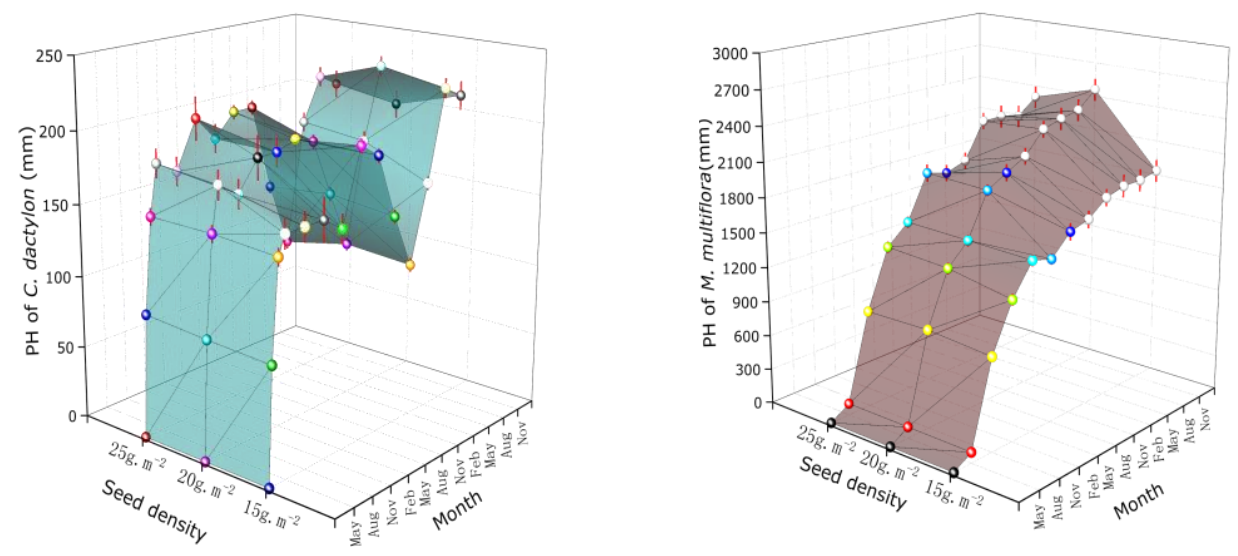

Figure 12. Dynamics of PH affected by seed density 


\section{Discussion}

It is a challenging task to stabilize and restore these damaged highway slopes by using suitable ecological restoration measures (Cao et al., 2010). The growth dynamics of different vegetation species has varying effects on community formation and may also reflect species differential responses to ecological restoration (Kadmon, 2016). PC, PD, and PH of pure-grass or pure-shrub revealed a sharp reduction, and consequently grassshrub is beneficial to community formation. Our results showed that the PC grew very fast in a month is consistent with the conclusion of the studies on deciduous species (Gadi et al., 2019). The results indicate that the growth dynamics of $C$. dactylon and $M$. multiflora depend on the seed scheme, grass-shrub ratio has a critical influence on PC, which is consistent with the conclusion that grass and shrub significantly increased PC (Schäfer et al., 2018). It is clear from our data to reveal that shrub positively affected grass survival and the shrub had positive effects on PC, PD, and PH (He et al., 2014). First, shrub canopy has a facilitative effect on grass due to more shade, lower temperature, lower radiation, and higher soil moisture (Jankju, 2013). Second, pure-grass or pure-shrub has limited slope surface cover, unable to retain moisture. Seedlings of pure-grass or pureshrub would be inferior to adaptation to harsh habitat conditions. Grass has advantages over deep-rooted shrubs in competition (Wang, 2014). However, grass had a negative feedback effect on the growth of the shrub and PC (Bai et al., 2018). The relationship between the shrub and the associated herbs was antagonistic. The final development is mainly herb-based or shrub-based communities, depending on the outcome of the confrontation between herbs and shrubs.

Previous studies showed that seed density played an important role in the stability and succession of ecological restoration (Bodziarczyk, 2001). The successful vegetation community establishment depends on the quality of seed density, germination conditions of seed, and growth conditions. Our results of more than $20 \mathrm{~g} \cdot \mathrm{m}^{-2}$ of seed density have a significant negative effect on the $\mathrm{PH}$ of $C$. dactylon and M. multiflora, which is consistent with the conclusion of high seed density producing low PD (Xu et al., 2016). Seed density has positive and negative effects on grass-shrub $\mathrm{PH}$. Only a little increasing amplitude of the average total PD of $C$. dactylon is emerged as the high seed density of Vetiveria zizanioides (Kozovits, 2014). This dynamic was linked to competition and soil nutrition of grass-shrub. High nitrogen fertilizer provided significant increases in PD at high seed density compared to low seed density (Elfadl et al., 2009). Therefore, PD can be improved by increasing fertility and high planting density.

It was proven in this study that topographic variables may have an impact on plant growth dynamics. Results indicated that the effect of topographic factors (slope gradient and slope aspect) on PD and PH is significant, which is consistent with the conclusion of slope aspect having significant effects on the PD of all plants and slope gradient only affecting the PD of shrubs significantly (Ou et al., 2011). In addition to topographic factors affecting growth dynamics, age cannot be ignored. The topographic factors did not influence newly sprouted culms during the stable period (Niu et al., 2020). The plants we studied are all in the growth period, especially the M.multiflora has substantial growth in the second and third years, which is greatly affected by the slope aspect and slope gradient. Climate influence on PC, PD, and PH determines whether ecological restoration can be successful (Fu et al., 2012). To improve the seed germination, the sowing time was chosen at $20-25^{\circ} \mathrm{C}$ in May. Altitude is also a topographic factor, which has an important impact on the ecological dynamics of vegetation (Wagner and Mitschunas, 
2008). Altitude is not involved in this paper, and further research in this area should be strengthened in the future.

The results highlight that it is essential to optimize the formulation of the four influencing factors of topographic factors and seed schemes in the scheme design before construction, and ensure that community formation of slope ecological restoration is quicker and economically feasible.

\section{Conclusion}

In this study, we investigated the effects of topographic factors (slope gradient and slope aspect) and seed schemes (grass-shrub ratio and seed density) on the dynamics of PC, PD, and PH of grass-shrub communities. Based on our results, we drew the following conclusions:

(1) Vegetation cover increased rapidly during the first four months. The change in PC after the fifth month was small. The average PC first increases and then decreases with the increase of slope gradient. The community formation period differed significantly for grass-shrub ratio $(P<0.05)$.

(2) The PD reached its maximum during the first two months and then decreased slowly. The slope gradient and seed density with peak value of C. dactylon PD are $45^{\circ}$ $\left(57 \mathrm{~N} \cdot \mathrm{dm}^{-2}\right)$ and $25 \mathrm{~g} \cdot \mathrm{m}^{-2}\left(41.67 \mathrm{~N} \cdot \mathrm{dm}^{-2}\right)$, respectively. PD differed significantly for grassshrub ratio.

(3) The slope gradient has an insignificant effect on the PH of $C$. dactylon, but the slope aspect has a significant effect on the $\mathrm{PH}$ of $M$. multiflora $(P<0.05)$. The seed density and grass-shrub ratio with the highest average $\mathrm{PH}$ are $20 \mathrm{~g} \cdot \mathrm{m}^{-2}$ and 1: 9 , respectively.

(4) The optimal conditions for the formulation of grass-shrub communities are as follows: slope gradient of $30^{\circ}-45^{\circ}$, slope aspect of south-facing, seed density of $20 \mathrm{~g} \cdot \mathrm{m}^{-2}$, grass-shrub ratio of 1:9. The formulation can promote the formation of ecological restoration community of rock slope more quickly, which can be extended to practical projects.

Acknowledgements. This research was funded by the National Natural Science Foundation of China (NSFC) [Grant Nos.51568022], Hubei Provincial Education Department Key Project [Grant No. 203201920903].

\section{REFERENCES}

[1] Allen, R., Pereira, L., Raes, D., Smith, M., Allen, R. G., Pereira, L. S., Martin, S. (1998): Crop Evapotranspiration-Guideline for computing crop water requirements. - Irrigation and Drain 56: 300.

[2] Bai, Y., She, W., Michalet, R., Zheng, J., Qin, S., Zhang, Y. (2018): Benefactor facilitation and beneficiary feedback effects drive shrub-dominated community succession in a semiarid dune ecosystem. - Applied Vegetation Science 21(4): 595-606.

[3] Cao, S. X., Ye, H. H., Zhan, Y. (2009): Cliff roads: An ecological conservation technique for road construction in mountainous regions of China. - Landscape and Urban Planning 94(3): 228-233.

[4] Cao, S., Xu, C., Ye, H., Zhan, Y., Gong, C. (2010): The use of air bricks for planting roadside vegetation: A new technique to improve landscaping of steep roadsides in China's Hubei Province. - Ecological engineering 36(5): 697-702. 
[5] Cavieres, L. A., Badano, E. I. (2009): Do facilitative interactions increase species richness at the entire community level? - Journal of Ecology 97(6): 1181-1191.

[6] Chen, Y., Xia, J., Zhao, X., Zhuge, Y. (2019): Soil moisture ecological characteristics of typical shrub and grass vegetation on Shell Island in the Yellow River Delta, China. Geoderma 348: 45-53.

[7] Cohen-Fernández, A., Naeth, M. (2013): Erosion control blankets, organic amendments and site variability influenced the initial plant community at a limestone quarry in the Canadian Rocky Mountains. - Biogeosciences 10(7): 5243-5253.

[8] Elfadl, E., Reinbrecht, C., Frick, C., Claupein, W. (2009): Optimization of nitrogenrate and seed density for safflower (Carthamus tinctorius L.) production under low-input farming conditions in temperate climate. - Field Crops Research 114(1): 2-13.

[9] Fan, J. C. (2013): Effect evaluation of shotcrete vegetation mulching technique applied to steep concrete-face slopes on a highway of Taiwan. - Paddy and Water Environment 11(1-4): 145-159.

[10] Fang, H., Ji, B., Deng, X., Ying, J., Zhou, G., Shi, Y., Xu, L., Tao, J., Zhou, Y., Li, C., Zheng, H. (2018): Effects of topographic factors and aboveground vegetation carbon stocks on soil organic carbon in moso bamboo forests. - Plant and Soil 433: 363-376.

[11] Freudenreich, H., Mußhoff, O. (2018): Insurance for Technology Adoption: An Experimental Evaluation of Schemes and Subsidies with Maize Farmers in Mexico. Journal of Agricultural Economics 69(1): 96-120.

[12] Fu, W., Huang, M. B., Gallichand, J., Shao, M. A. (2012): Optimization of plant coverage in relation to water balance in the Loess Plateau of China. - Geoderma 173-174: 134-144.

[13] Gadi, V. K., Garg, A., Rattan, B., Raj, P., Gaurav, S., Sa, S., Sahoo, L., Berretta, C., Peng, L. (2019): Growth dynamics of deciduous species during their life period: A case study of urban green space in India. - Urban Forestry \& Urban Greening 43: 126380.

[14] Garg, V. K., Garg, A., Prakash, S., Wei, L., Andriyas, S. (2018): A non-intrusive image analysis technique for measurement of heterogeneity in grass species around tree vicinity in a green infrastructure. - Measurement 114: 132-143.

[15] Hobbs, R. J., Harris, J. A. (2001): Restoration ecology: repairing the earth's ecosystems in the new millennium. - Restoration ecology 9(2): 239-246.

[16] Jankju, M. (2013): Role of nurse shrubs in restoration of an arid rangeland: Effects of microclimate on grass establishment. - Journal of Arid Environments 89: 103-109.

[17] Kadmon, R. (2016): Size asymmetry of resource competition and the structure of plant communities. - Journal of Ecology 104(4): 899-910.

[18] Kim, M., Lee, W.-K., Son, Y. W., Yoo, S., Choi, G. M., Chung, D. J. (2017): Assessing the impacts of topographic and climatic factors on radial growth of major forest forming tree species of South Korea. - Forest Ecology and Management 404: 269-279.

[19] Kozovits, A. R. (2014): Growth of cerrado native species and of Vetiveria zizanioides in colluvium of gullies. - Ciencia Florestal 24(4): 843-855.

[20] Lei, K., Pan, H., Lin, C. (2016): A landscape approach towards ecological restoration and sustainable development of mining areas. - Ecological engineering 90: 320-325.

[21] Leung, A. K., Garg, A., Ng, C. W. W. (2015): Effects of plant roots on soil-water retention and induced suction in vegetated soil. - Engineering Geology 193: 183-197.

[22] Li, X., Han, Y., Wang, G., Feng, L., Wang, Z., Yang, B. (2020): Response of cotton fruit growth, intraspecific competition and yield to plant density. - European Journal of Agronomy 114: 125991.

[23] Liu, H. W., Feng, S., Garg, A., Ng, C. W. W. (2018): Analytical solutions of pore-water pressure distributions in a vegetated multi-layered slope considering the effects of roots on water permeability. - Computers and Geotechnics 102: 252-261.

[24] Manzaneda, A. J. (2005): Effects of microsite disturbances and herbivory on seedling performance in the perennial herb Helleborus foetidus (Ranunculaceae). - Plant Ecology 179(1): 73-82. 
[25] Ni, J. (2018): Modelling hydro-mechanical reinforcements of plants to slope stability. Computers and Geotechnics 95: 99-109.

[26] Niu, Z., Li, C., Shi, Y., Chen, G., Mei, T., Zhou, Y., Xu, L., Zhou, G. (2020): Topography Significantly influences the Growth Dynamics of Moso Bamboo Along a 10-year Chrono Sequence Following Afforestation. - Journal of Sustainable Forestry, pp. 1-19.

[27] Olsen, J. (2006): Influence of sowing density and spatial pattern of spring wheat (Triticum aestivum) on the suppression of different weed species. - Weed Biology \& Management 6(3): 165-173.

[28] Ou, Y. D., Su, Z. Y., Li, Z. K., Lin, Y. H. (2011): Effects of topographic factors on the distribution patterns of ground plants with different growth forms in montane forests in North Guangdong, China. - Journal of Applied Ecology 22(5): 1107.

[29] Schäfer, D., Prati, D., Schall, P., Ammer, C., Fischer, M. (2019): Exclusion of large herbivores affects understorey shrub vegetation more than herb vegetation across 147 forest sites in three German regions. - PLOS ONE 14(7): e0218741.

[30] Schob, C. (2013): Direct and indirect interactions co-determine species composition in nurse plant systems. - Oikos 122(9): 1371-1379.

[31] Shao, Q. (2014): Effectiveness of geotextile mulches for slope restoration in semi-arid northern China. - Catena 116: 1-9.

[32] Song, Q. H. (2015): Spatial distribution patterns of specific root lengths of Avena sativa L. and Vicia villosa Roth in mixed-sowing grassland under density dependence in northern slope of Qilian Mountains. - Chinese Journal of Ecology 34(2): 497-503.

[33] Tardieu, F., Draye, X., Javaux, M. (2017): Root Water Uptake and Ideotypes of the Root System: Whole-Plant Controls Matter. - Vadose Zone Journal 16(9): 1-10.

[34] Teixeira, A. F. S., Silva, J. S., Vilela, L. A. F., Costa, P. F., Moreira, F. M. S. (2019): Microbiological indicators of soil quality under native forests are influenced by topographic factors. - Anais da Academia Brasileira de Ciências 91(4).

[35] Vietor, D. M., Schnell, R. W., Munster, C. L., Provin, T. L., White, R. H. (2010): Biosolid and alum effects on runoff losses during turfgrass establishment. - Bioresour Technol 101(9): 3246-3252.

[36] Wagner, M., Mitschunas, N. (2008): Fungal effects on seed bank persistence and potential applications in weed biocontrol - A review. - Basic \& Applied Ecology 9(3): 191-203.

[37] Wang, J (2014): Analysis on the influencing factors of vegetation growth in highway slope. - Highway 1: 200-204.

[38] Xu, J., Zhang, Y., Cui, G. L., She, Y. H., Li, L. Y. (2016): Study on influence factors of seed germination and seed growth of Lonicera macranthoides. - China Journal of Chinese Materia Medica 41(1): 51-55.

[39] Yang, Y., Yang, J., Zhao, T., Huang, X., Zhao, P. (2016): Ecological restoration of highway slope by covering with straw-mat and seed with grass-legume mixture. - Ecological engineering 90: 68-76.

[40] Yang, X., Wang, J., Zhu, C., He, M., Gao, Y. (2019): Effect of wetting and drying cycles on microstructure of rock based on SEM. - Environmental earth sciences 78(6): 183.

[41] Zhao, G. (2020): Effects of shading and herb/liana eradication on the assembly and growth of woody species during soil translocation in Southwest China. - Ecological engineering 144: 105704.

[42] Zhao, R. M., Zhang, H., An, L. Z. (2020): Spatial patterns and interspecific relationships of two dominant cushion plants at three elevations on the Kunlun Mountain, China. Environmental Science and Pollution Research 27(3): 11-21.

[43] Zhou, L. (2016): Thinning increases understory diversity and biomass, and improves soil properties without decreasing growth of Chinese fir in southern China. - Environmental science and pollution research international 23: 1-16.

[44] Zhu, H., Zhang, L. (2015): Evaluating suction profile in a vegetated slope considering uncertainty in transpiration. - Computers and Geotechnics 63: 112-120. 